\title{
Cooperative Development of High Level Professional Marine Engineering Groups
}

\author{
Mingyu Wang ${ }^{1, a}$, Shaojun Zhang ${ }^{1, b^{*}}$, Chunxiao Jiang ${ }^{1, c}$, \\ Chengda Zhang ${ }^{1, \mathrm{~d}}$ and Fengguang $\mathrm{Jia}^{1, \mathrm{e}}$ \\ ${ }^{1}$ College of Naval architecture and Marine Engineering, Shandong Jiaotong University, 1508 \\ Hexing Road, 264310, Weihai, China \\ avicsee@163.com, bsjzhangwh@163.com, cytu102@163.com, ${ }^{\mathrm{d}} 1345468351 @ q q . c o m$, \\ e942898493@qq.com \\ * The Corresponding Author
}

Keywords: Professional groups; Cooperative development; Marine engineering; Supply side reform

\begin{abstract}
A marine engineering professional group is set up from the perspective of industrial clusters. The professional group is a new way for maritime universities to integrate into the regional economic development and to realize the opening of school. The principles of setting up professional groups in maritime universities are: the development stage of moderately advanced industrial clusters, the characteristic industrial clusters based on the region, the integrated arrangement and convergence of different educational professional groups, and the combination of resources. We optimize the professional supply side structure, innovate the training mode, improve the quality of applied professionals training, and solve the problem of "last mile" in the employment of graduates. Excellent international and sandwich type personnel training mode are also implemented to achieve marine related professionals training mode with international standards, to complete the adjustment and optimization of the supply side structure of professional groups. Take this opportunity to comprehensively promote the reform of relevant professional curriculum system and teaching content, and play an exemplary and radiate role in the professional development of similar universities.
\end{abstract}

\section{Introduction}

Along with 2015 China ocean development report put forward the construction of marine power strategy and The Belt and Road national strategy. Shipping economy will usher in a new challenge and opportunity. China accounts for 2 of 10 largest international shipping centers, and 7 of the 10 busiest ports in the world, and China has become a shipping center. Shandong Province is an important marine province. It is the national and local strategic demand to develop the shipping economy. Naturally, the demand for professionals training is urgent. By 2020, the total demand for marine resources will exceed 3 million. Comprehensive supply ship engineering, marine engineering, electronic and electrical, ship navigation, port machinery professional 2017 graduates of Shandong Jiaotong University, supply and demand ratio is expected to exceed 1:7. The overall supply and demand of graduates in 2018 will more than 1:10. Although the sea related major is expected to be promising, the quality of employment is still not ideal. Because there are some problems in the supply side structure of marine professionals training, and the training quality of applied professionals is not good enough, and the training of applied professionals is not consistent with market demand.

Nautical education is characterized by professionalism, practicality, regionally and openness [1, 2]. It has a highly coordinated relationship with the industrial economic structure and the characteristic industrial economy in its area. From the perspective of economic development, different economic regions tend to have different economic foundation, industry in different stages of development and the level of productivity development. From the perspective of economic structure, different economic regions also tend to have different natural resource endowments, industrial structure and economic development strategic direction. The structure and development of the regional economy directly determine the quantity and quality of the local professionals, even the knowledge and ability structure of 
the professionals[3]. Therefore, the higher education, which is directly oriented to the professionals market and serving the regional economy, should be set up and adjusted according to the characteristics of the local regional industrial economy.

At present, in the process of regional economic development in China, the effect of industrial agglomeration is becoming obvious, and the industrial cluster is formed. Industrial cluster is the result of adjustment and optimization of industrial structure. It is also a product of industrial development to a certain stage, and it is also a sign of maturity of regional industrial economic development [4]. The development of industrial clusters has promoted the construction and development of professional groups in nautical colleges[5]. The professional group, with a particular focus on the core professional as a leader, including a number of services in the same set of technologies and services in the field of professional, these professionals have the same or similar technical requirements of theoretical foundation and ability, can share the teachers, curriculum, practice venues such as teaching resources, has formed the scale economy and enhance the input-output ratio of education itself and save the cost of education, highlighting the maritime colleges historical mission and reason for action [6, 7]. Based on the external motivation of the maritime colleges professional group setting and development are analyzed, focusing on analysis of coordination mechanism of industry cluster and professional groups, can provide a useful theoretical reference for regional maritime colleges professional group layout and settings $[8,9]$.

\section{Relationship Between the Marine Professional Group and the Shipbuilding Industry Chain}

Up to December 31, 2017, there were 1.37 million registered crew members in China, of which 470000 ships were sailing internationally. Now the shipping professionals' education in China including: Dalian Maritime University in the north, Shanghai Maritime Univeristy in the south, and Wuhan University of Technology in the center. All regions rely on colleges and universities and take shipping enterprises as the platform to build the regional shipping professionals, forming local advantages [10]. Shandong Province as a big seafarer province, accounting for the total number of senior crew $18 \%$. Shandong Jiaotong University locates the geographical position is superior, the navigation professional is one of the most characteristic. Shandong Jiaotong University has always attached great importance to education reform and practice of navigation, starting from the background of international maritime education. According to the international maritime colleges practice to STCW78/10 International Convention for guidance, and actively explore the training program for maritime professionals to adapt to the international competition, a series of teaching reform, has formed a set of scientific personnel training mode. and constantly improve the level of professional teaching. To speed up the construction of the marine related specialty groups is the need for shipping professionals training in Shandong Province, which enables Shandong Jiaotong University to play a leading role in the development of Shandong shipping market.

As an important part of the sea in the development of the road, sea, air and rail strategy, the sea related professional group covers major sea related majors in the strategy of developing the road, sea, air and rail strategy of Shandong Jiaotong University. This professional group covers the whole life cycle of ship design, construction, operation, maintenance and dismantling. Among them, engineering major, marine engineering and marine technology are the key construction specialties of the famous application type famous schools in Shandong. Based on the theory of ship and ocean engineering and electrical engineering, the marine engineering specialty is based on information technology, digitalization and intelligent turbine as the professional development direction. So as to train high-quality applied professionals that meet the needs of the first line of production and management in marine transportation enterprises. Marine engineering majors are mainly trained to meet the development needs of China's shipbuilding industry. They are competent for the design, construction and service of ships, yachts and marine structures. They have the international vision, innovation spirit and growth ability of front-line engineers and managers. The major of ship electronic and electrical engineering is to train engineers or managers who have basic theory and professional knowledge of ship electronic and electrical equipment management, have high foreign language level and computer application ability, 
and can manage, maintain and repair modern electronic equipment of marine vessels. Marine technology professional training to master the theory and practice of modern navigation skills, with ship driving and transportation management ability, development, competence of modern shipping industry has the international competitive ability of senior applied professionals of navigation. On the basis of mechanical and electronic engineering mechanics, mechanical, electrical and hydraulic theory, the transportation equipment manufacturing industry in port machinery manufacturing, maintenance and application for professional development, cultivate professionals to meet the machinery, transportation, ports and other industries the first line of production and management needs. The relationship between sea related professional groups and the shipbuilding industry chain is shown in the following chart, Figure 1.

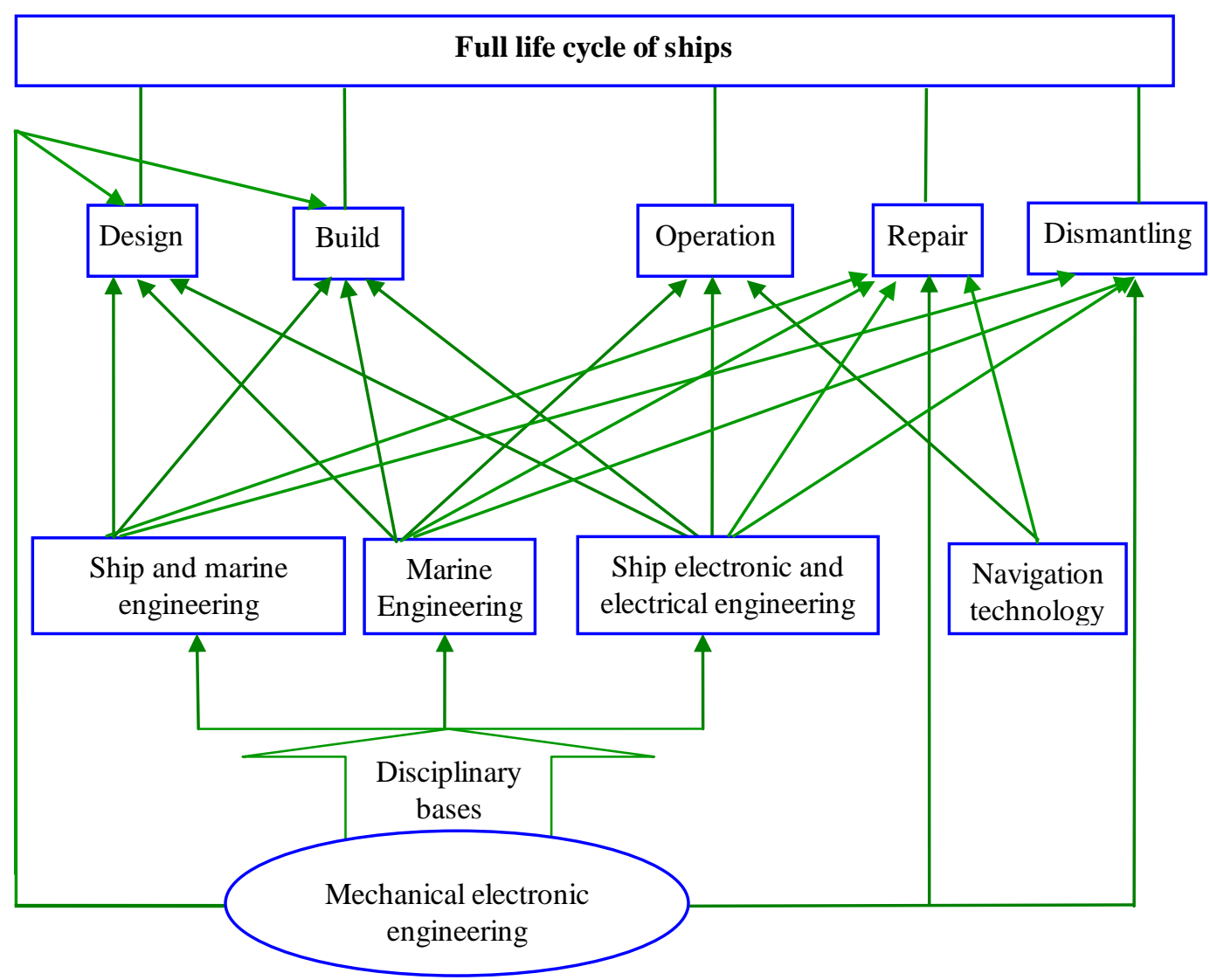

Figure 1. The relationship between sea related professional groups and the shipbuilding industry chain

\section{Cooperative Education Mechanism}

Clear the Goal of Professionals Training. The professional professionals training objectives for training with the International Maritime Organization (IMO) to develop the international seafarer training, International Convention on standards, with mechanical principle, turbine system management and maintenance and good English skills and practical knowledge. They should have good occupation ethics and the spirit of dedication, and high-end skilled professionals in the modernization of marine turbine technology management in shipping enterprises, shipyards and shipping enterprises. Marine engineering is to maintain the professionals training characteristics, give full consideration to the post competency, international general, law and military characteristics. In the process of quality education, we could strengthening the subject consciousness, legal consciousness, management consciousness, and practical ability. For other majors, in the process of quality education, we should pay more attention to the cultivation of students' innovative spirit and practical ability. 
Student Training Mode and International Integration. We should optimize the professional supply side structure, innovate the training mode of professionals, improve the quality of applied professionals training, and solve the last mile problem of navigation teaching graduates. Pilot implementation of excellent international and sandwich type personnel training mode, to achieve marine related professionals training mode in line with international standards, to complete the adjustment and optimization of the supply side structure of professional groups. Applied professionals in the new training mode, in the outstanding occupation ability training as the main line of the premise, in cooperation with the shipping enterprise running, hierarchical implementation of the excellent international and sandwich type training needs, at the same time the shipping enterprises as training ship for the school provide students with navigational practice, as teachers contact advanced cutting-edge marine engineering management technology.

Improve the collaborative education mechanism and actively promote the deep cooperation between schools, enterprises, and schools, so as to achieve the docking between professional chain and industry chain, curriculum content and professional standard, teaching and production process. In order to improve the proportion of the practice class, the proportion of the professional practice credits to the total credit ratio is not less than $30 \%$. We should strengthen the reform of curriculum, develop professional courses and open courses online so as to meet the needs of students' diversified learning. We should enhance the supply side structure reform of marine related professionals, improve innovation and entrepreneurship education, and improve employability and employment quality, so that the total employment rate of graduates can reach over $97 \%$.

\section{Cooperative Development Mechanism of the Professional Group}

Industrial cluster has an obvious life cycle. Under normal circumstances, the evolution of industrial clusters will follow the following stages: germination, growth, maturity, decline, and exit with the success of upgrading, and enter the two stage of entrepreneurship development. From the time point of view, every stage of development to the next stage of the cycle according to the nature of different industries and is not exactly the same. From the perspective of space, the development of industrial clusters are the same in different regions may not agree, for example, port logistics industry developed in Shanghai, Ningbo and other regions already in the late growth stage of this stage to the mature stage of the early stage, but in the early stage of growth in Shandong. The structure of professionals demand is different in different stages of industrial clusters and different stages of development of industrial clusters. The characteristics of higher education also decide that the establishment of professional groups in Maritime Universities should be integrated with industrial clusters.

Based on this research topic, we can simplify the structure of professionals demand into three levels: high, medium and low. According to the empirical data, the industrial cluster of high and low-end professionals demand structure is more pyramid, but has not ruled out in the stage of development of some industries showed inverted trapezoid, spindle and dumbbell shaped etc. Shandong port logistics industry cluster as an example, because it is still in the initial stage of growth, this stage requires massive investments in ports, information platform and other infrastructure. It is urgent needing to do the planning of logistics project design work.

In turn, the professional setting of maritime colleges and the cultivation of professionals will directly affect the area economy and the next few years the supply of professionals, and then influence the industrial economy healthy and sustainable development of higher education, therefore, also has a leading role in the regional economy and anti. Of course, under the background of the integration of professionals market and free flow, professionals from marine colleges and universities in a certain area may be outflowing, but professionals from marine universities outside the region may also enter the region. In addition, due to the fact that the professionals trained by Maritime Universities are different from the general professionals trained by ordinary universities, they often have strong situational dependence. That is to say, the professionals trained by universities in the region have a high degree of agreement with the local characteristic industrial clusters that more applicable to local businesses, which restricts the cross regional mobility of high-end skilled professionals. 


\section{Popularizing the Value of Application}

Optimize the professional supply side structure, innovate the training mode of professionals, improve the quality of applied professionals training, and solve the problem of "last mile" in the employment of navigation teaching graduates. Pilot implementation of excellent international and sandwich type personnel training mode, to achieve marine related professionals training mode in line with international standards, to complete the adjustment and optimization of the supply side structure of professional groups. Take this opportunity to comprehensively promote the reform of relevant professional curriculum system and teaching content, and play an exemplary and radiate role in the professional development of similar universities.

\section{Acknowledgments}

This research was supported by Shandong graduate student tutor guidance ability promotion project.

\section{References}

[1] O. Köckritz, M. Kurowski, D. Grunert et al. From Nautical Path Planning in ECDIS to Their Realisation Applied for Fully Actuated Ships, IFAC. 49, 23(2016)115-120.

[2] R. Kiplimo, B.W. Ikua. Maritime Education Training in East Africa Region: Current Status, Procedia Engineering. 194(2017)351-355.

[3] E. Gissi, J.L.S. Vivero Exploring marine spatial planning education: Challenges in structuring transdisciplinarity, Marine Policy. 74(2016)43-57.

[4] L.D. Fan, J.G. Fei, U. Schriever et al. A critical examination of the seafaring English education and training in China, Marine Policy. 86(2017)56-63.

[5] V.R. Kamat. Dispossession and disenchantment: The micropolitics of marine conservation in southeastern, Tanzania Marine Policy. 88(2018)261-268.

[6] B.L. Hartley, R.C. Thompson, S. Pahl. Marine litter education boosts children's understanding and self-reported actions, Marine Pollution Bulletin. 90(2015)209-217.

[7] L.S.L. Teh, L.C.L. Teh, G. Jolis. An economic approach to marine megafauna conservation in the coral triangle: Marine turtles in Sabah, Malaysia, Marine Policy. 89(2018)1-10.

[8] L.A. Annika, L. Peterson, T. Hillman et al. Sharing repertoires in a teacher professional Facebook groupLearning, Culture and Social Interaction. 15(2017)44-55.

[9] Peng L. Individual Choice and Reputation Distribution of Cooperative Behaviors among Heterogeneous Groups. Chaos, Solitons \& Fractals, 2015, 77: 39-46.

[10] R.P. Rooderkerk, K.H. Pauwels. No Comment? The Drivers of Reactions to Online Posts in Professional Groups, Journal of Interactive Marketing. 35(2016)1-15.

[11] J.D. Chen, Y. Wang, M.L. Song. Analyzing the decoupling relationship between marine economic growth and marine pollution in China, Ocean Engineering. 137(2017)1-12. 